\title{
Arah Pergerakan Perubahan Leksikon Tipe Konservatif Pada Enklave Jawa
}

\section{Carita, Banten}

\author{
M. Suryadi \\ Fakultas Ilmu Budaya, Universitas Diponegoro, \\ mssuryadi07@gmail.com
}

\begin{abstract}
The purpose of this research is to find the direction of movement and change of lexicon which is located in Javanese enclave, Carita, Banten. Methods of data collection using observation and interview methods: tapping techniques, fishing techniques, recording techniques, and tekik notes. The method of analysis used is reconstruction method and tree root direction method

The research findings that the Java enclave region, Carita, in the Sundanese language area, still holds many relics and original lexicons. The relics lexicon form is a lexicon that is derived directly from the ancient Javanese language without any slight change, either form or meaning. The original form of lexicon is a lexicon that changes at the time of inheritance. Changes that occur in the lexicon can be explained through linguistic rules. The direction of the movement of the relics and the original form of the Javanese dialect of Carita has a tendency of vertical direction, ie the direct inheritance direction of the ancient Javanese language. The direction of the movement of innovative shape changes tends to be horizontal, ie the direction of change that adapts the rules of Sundanese and Malay.
\end{abstract}

Keywords: Carita, innovation, original, Java enclave, relics

\section{Intisari}

Tujuan penelitian adalah mengkaji arah pergerakan perubahan leksikon yang berada di kantung Jawa, Carita, Banten. Metode pengumpulan data menggunakan metode observasi dan interview: teksnik sadap, teknik pancing, teknik rekam, dan tekik catat. Metode analisis yang digunakan adalah metode rekonstruksi dan metode arah akar pohon.

Temuan penelitian bahwa wilayah kantung Jawa, Carita, di wilayah pemakaian bahasa Sunda, masih banyak menyimpan leksikon-leksikon relik dan asli. Bentuk leksikon relik adalah leksikon yang diturunkan langsung dari bahasa Jawa kuna tanpa mengalami perubahan sedikit pun, baik bentuk maupun arti. Bentuk leksikon asli adalah leksikon yang mengalami perubahan pada saat pewarisan. Perubahan yang terjadi pada leksikon dapat dijelaskan melalui kaidah linguistik.Arah pergerakan perkembangan bentuk relik dan asli bahasa Jawa dialek Carita memiliki kecenderungan arah vertikal, yakni arah pewarisan yang langsung dari bahasa Jawa kuna. Arah pergerakan perubahan bentuk inovatif cenderung horizontal, yakni arah perubahan yang menyesuaikan kaidah bahasa Sunda dan Melayu.

Kata kunci: asli,Carita, inovasi, kantung Jawa, relik 


\section{Pendahuluan}

Bahasa Jawa memiliki multi keistimewaan. Keistimewaan inilah yang selalu menjadi daya tarik luar biasa bagi pakar bahasa, pecinta bahasa, dan pengguna bahasa sendiri. Namun, dibalik itu juga banyak yang menguatirkan perkembangan terhada bahasa Jawa itu sendiri. Fenomena ini sebagai realita yang tidak dapat dipungkiri bahwa dibalik keistimewaan masih ada kecemasan. Sisi positif yang dapat ditarik adalah bahasa Jawa sebagai sumber inspirasi terhadap kemajuan ilmu linguistic.

Keistimewaan yang lekat dimiliki bahasa Jawa adalah memiliki cakupan wilayah yang cukup luas, bahkan di luar wilayah Nusantara, missal Suriname. Di wilayah Nusantara pun berkembang sampai di luar Pulau Jawa (salah satu dampak keberhasilan program transmigrasi). Keistimewaan lain adalah jumlah penutur yang cukup besar di antara bahasa-bahasa Austronesia (Pusat Bahasa, nd:1). Merujuk dari luas wilayah penggunaan bahasa Jawa akan muncul varian-varian bahasa Jawa yang berkembang menjadi sebuah dialek dan sub-sub dialek. Banyak dialek bahasa Jawa berkembang sesuai warna local dimana bahasa Jawa tersebut digunakan, yakni muncul dialek Banyumas, dialek Banyuwangi, dialek Cirebon, dialek Indramayu,dialek Osing,dialek Surabaya, dialek Tegal, dan dialek Tengger (cf. Iskandarwasid, 1985).

Keistemewaan lain terkait dengan luasnya cakupan wilayah adalah munculnya kantung-kantung (enclave) Jawa. Enkalve Jawa ini muncul akibat migrasi penuturnya, relasi historis, kontak ekonomi, dana atau kontak budaya. Banyak eklave Jawa yang terdapat di pulau Jawa, yakni di wilayah Patuanan Kabupaten Indramayu; Panyutran dan Sidomulih di Kabupaten Ciamis (Nothofer, 1990:1); dan Carita di Kecamatan Carita, Kabupaten Pandeglang, Propinsi Banten (Suryadi, 1997:1).

Enklave Jawa adalah pemakaian bahasa Jawa yang berada di wilayah pakai bahasa lain (non bahasa Jawa). Fitur yang paling menonjol di daerah eklave Jawa adalah terjadi perubahan dan pergeseran bentuk dan arti, kaya dengan fenomena duplet leksikon, kaya dengan inovasi leksikal baik secara internal maupun eksternal, serta yang paling menarik dan menjadi focus kajian penelitian ini adalah terpeliharanya bentuk leksikon konservatif.

Adapun rumusan masalah yang diangkat dalam penelitian ini adalah bagaimana leksikon konservatif yang tetap bertahan di wilayah enkalve Jawa dan bagaimana arah pergerakan perkembangan leksikon konservatif yang tetap dipertahankan di wilayah enkalve Jawa. 
Penelitian ini tidak dapat dilepaskan oleh peneltian-penelitian sebelumnya terutama terkait dengan penelitian varian leksikon pada dialek-dialek di wilayah penggunaan bahasa Jawa dan penelitian yang gayut dengan persebaran bahasa Jawa akibat migrasi atau kontak bahasa. Penelitian tersebut digunakan sebagai landasan teori dan mempertajam analisis. Beberapa penelitian yang digunakan sebagai bahan rujukan, sebagai berikut.

Migrasi arah persebaran bahasa Jawa di bagian barat terutama di wilayah Banten diungkapkan oleh Patmadiwiria (1977:1) bahwa bahasa Jawa di wilayah Banten atau Bahasa Jawa-Banten telah lama berpisah dengan sumber asalnya, diperkirakan pada abad ke-17. Dihoptesiskan bahasa Jawa di pantai Utara Jawa barat masih mempunyai sejumlah kosakata dan struktur kata yang pernah berkembang di Jawa Tengah pada permulaan abad ke-17, rujukan ini yang memperkuat hipotesis bahwa enclave Jawa masih banyak menyimpan bentuk-bentuk leksikon konservatif dan relik.

Nothofer (1977: 1) melakukan perunutan terhadap persebaran bahasa Jawa di wilayah bagian barat. Hasil temuannya adalah ditemukan banyak dialek, dengan dasar perhitungan dialektometri dengan acuan standar manakala perbedaan terjadi perbedaan prosentase antara 51-80\% dianggap sebagai dialek yang berbeda. Dengan dasar perhitungan tersebut ditemukan delapan dialek, sebagai berikut.

1) Dialek Banten meliputi wilayah (1) Bojonegoro, (2) Kesemen, (3) Pontang, (4) Kronjo, (5) Kosambironyok, (6) Cilowong,(7) Cibogo, dan (8) Julang.

2) Dialek Krawang meliputi wilayah (1) Sungaibuntu, (3) Tanjungtiga, (4) Binong, dan (5) Cigugur.

3) Dialek Bayur.

4) Dialek Indramayu meliputi wilayah (1) Eretan Wetan, (2) Jatimunggul, (3) Lohbener, (4) Sumber, (5) Patuanan, dan (6) Jayawinangun.

5) Dialek Cirebon meliputi wilayah (1) Ciwaringin, (2) Suranenggala Kidul, (3) Kecomberan, (4) Astanajapura, dan (5) Kalibuntu.

6) Dialek Banyumas meliputi wilayah (1) Brebes, (2) Tegal, (3) Ketanggungaan, (4) Sembung, (5) Prupuk, (6) Kalilangkap, (7) Muarareja, (8) Sindangjaya, (9) Rajagwesi, (10) Galuh Timur, (11) Tayem, (12) Ditemu, (13) Luwijawa, (14) Kedawung, (15) Sambirata, (16) Pengadegan, (17) Gandrungmanis, (18) Grujugan, (19) Karangduren, (20) Majapura, (21) Jojogan, (22) Api-api, (23) Lolong, (24) Kalibening, (25) Danareja, (25) Gumawang, (26) Buluspesantren, 
(27) Plumbon, (28) Prigi, (29) Pejawaran, (30) Wonobodro, (31) Ponowareng, (32) Tegalombo 1, (33) Bojong, (34) Tegalombo 2, (35) Brunorejo, dan (36) Wareng,

7) Dialek Ciamis meliputi wilayah (1) Panyutran dan (2) Sidamulih.

8) Dialek Yogya meliputi wilayah (1) Banaran dan (2) Mula.

Hasil penelitian Nothofer (1977) memperlihatkan bahwa persebaran bahasa Jawa dibagian barat cukup luas, dialek yang memiliki cakupan paling luas adalah bahasa Jawa dialek Banyumas.

\section{Metode Penelitian}

Lokasi Penelitian berada di Desa Carita terletak di Pantai Utara bagian Barat pulau Jawa, secara administratif berada di Kecamatan Carita, Kabupaten Pandeglang, Propinsi Banten. Dasar pertimbangannya adalah Desa Carita sebagai wilayah enklave Jawa (kantung Jawa), yakni wilayah penggunan bahasa Jawa yang berada di tengahtengah wilayah pemakaian bahasa Sunda. Sekaligus muncul fenomena lain yakni enclave Jawa yang berhimpitan dengan pemakaian bahasa Melayu.

Metode pengumpulan data, untuk mencapai tujuan penelitian, langkah awal yang dilakukan adalah memanfaatkan metode observasi/simak dengan teknik dasarnya berwujud teknik sadap. Teknik lanjutan berwujud teknik simak bebas libat cakap (Sudaryanto, 1988). Sumber data yang digunakan adalah teks dan manuskrip.

Metode kedua yang dimanfaatkan dalam mengumpulkan data adalah metode interview atau cakap, teknik dasar yang digunakan adalah teknik pancing. Pada metode ini teknik lanjutan yang dimanfaatkan adalah teknik cakap semuka, teknik rekam, dan teknik catat. Sumber data yang digunakan adalah informan dengan persyaratan tertentu: menguasai bahasa Jawa Carita dan tinggal di wilayah penelitian dua generasi sebelumnya.

Wujud data adalah kosakata dasar. Pembatasan pada kosakata dasar, berangkat dari asumsi bahwa kosa katadasar: (1) sukar sekali berubah; (2) memiliki retensi atau ketahanan yang konstan sepanjang masa, (3) nilai perubahannya untuksetiap bahasa adalah sama (Swadesh, 1955).

Metode analisis yang digunakan untuk membedah data adalah metode rekonstruksi (Nothofer, 1987; Hock, 1988)dan metode arah akar pohon.Metode rekonstruksi digunakan untuk menelusuri alur pewarisan leksikon yang ditemukan terhadap proto-leksikalnya. Metode ini memanfaatkan hasil rekonstruksi Proto-Malayo- 
Javanic/PMJ (Nothofer, 1975) dan rekonstruksi Proto-Austronesia/PAN (Wurm-Wilson 1978).

Metode arah akar pohon digunakan untuk menelusuri arah perkembangan sebuah leksikon sehingga dapat diketahui alur pewarisannya dan, kepengaruhan terhadap bahasa lain, yang sekerabat.

\section{Hasil dan Pembahasan}

\section{Kondisi Kebahasaan Bahasa Jawa Dialek Carita}

Secara alami sebenarnya kondisi kebahasaan suatu wilayah tidak terlepas dari letak geografisnya. Berdasarkan letak geografi, bahasa Jawa Dialek Carita (BJC) berada di tengah-tengah daerah pemakaian bahasa Sunda (BS), dan sekaligus berhimpitan dengan pemakaian bahasa Melayu (BM). Letak geografi ini memicu untuk terjadinya kontak bahasa Jawa-Sunda-Melayu.

Kontak bahasa merupakan salah satu penyebab terjadinya perubahan suatu bahasa (perubahan dan pergeseran) lahirlah bentuk-bentuk inovasi dan pinjaman. Namun, tidak menutup kemungkinan terjadi bentuk relik, asli, dan konservatif. Hal ini, tidak dapat dilepaskan dari sikap bahasa penuturnya.

Sikap bahasa sangat berpengaruh dalam pemertahanan terhadap bahasanya. Sikap yang ditunjukkan oleh penutur bahasa Jawa dialek Carita cukup positif terutama terkait rasa emosional kekeluargaan. Bahasa Jawa dialek Carita masih produktif dalam penggunaan tuturan sehari-hari terutama dalam ranah keluarga. Pemanfaatan penggunaan bahasa Jawa dialek Carita kerap kali digunakan dalam percakapan orang tua, upacara adat, dan tetembangan, walaupun kondisi ini mulai jarang ditemukan, namun sebagai upaya pelestarian bahasa Jawa dialek Carita.

\section{Pemilahan Bentuk Relik, Asli dan Inovasi}

Pemilahan bentuk leksikon dalam penelitian ini diberikan batasan operasional agar tidak menimbulkan kekaburan atau ambiguitas. Leksikonrelik adalah leksikon yangditemukan dalam bahasa Jawa dialek Carita, yang melalui penelusurannya diduga diturunkan dari bahasa Jawa kuna. Proses penurunannya masih konservatif, belum mengalami perubahan sedikit pun, baik pada bentuk (form) maupun artinya (meaning).

Leksikon asli adalah leksikon yang ditemukan dalam bahasa Jawa dialek Carita, yang dalam penurunannya berasal dari bahasa Jawa. Proses penuruannya telah mengalami perubahan internal. Prose perubahan tersebut dapat dijelaskan melalui kaidah linguistik. 
Leksikon inovasi adalah leksikon bahasa Jawa dialek Caritayang telah mengalami perubahan, baik perubahan internal maupun eksternal, namun perubahan tersebut tidak dapat dijelaskan melaui kaidah linguistik.

\section{Arah Pergerakan Perubahan Leksikon Bahasa Jawa Dialek Carita}

Arah pergerakan perubahan leksikon dalam bahasa Jawa dialek Carita dapat dibedah melalui perpaduan dua metode yakni metode rekonstruksi dan metode arah akar pohon. Kedua metode ini dapat bermanfaat untuk menelusuri arah perkembangan sebuah leksikon sehingga dapat diketahui alur pewarisannya dan, kepengaruhan terhadap bahasa lain, yang sekerabat. Adapun beberapa leksikon yang diketahui arah pergerakan perubahannya, diperikan sebagai berikut.

\section{Leksikon Relik: Doh 'Jauh'}

Leksikon doh yang kerapkali bervarian dengan bentuk adoh 'jauh' dikategorikan sebagai leksikon relik. Leksikondoh 'jauh' dalam proses pewarisannya tidak mengalami perubahan sedikit pun dari bahasa Jawa kuna: doh 'jauh', baik pada bentuk maupun arti. Leksikon Jawa kuna doh 'jauh' diturunkan langsung dari Proto Melayu-Jawa *zauh ‘jauh’. Adapun proses alur pergerakan pewarisannya, sebagai berikut.

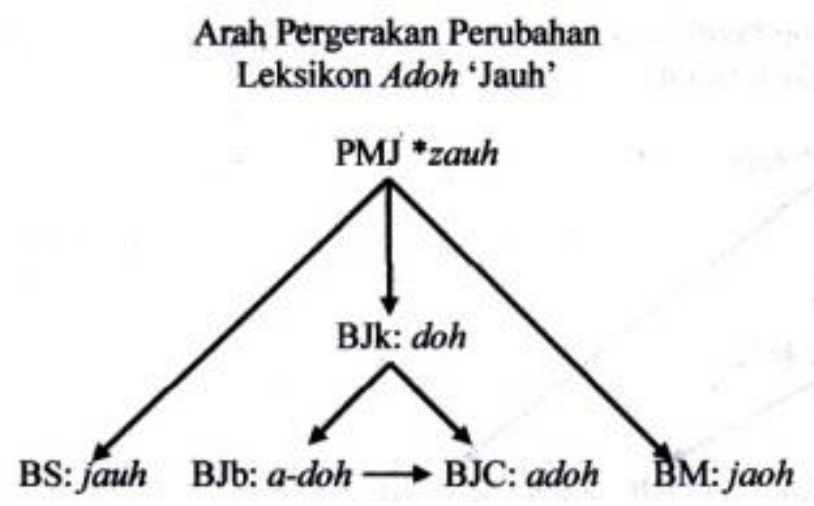

\section{Leksikon Relik: Kacan 'Kacang'}

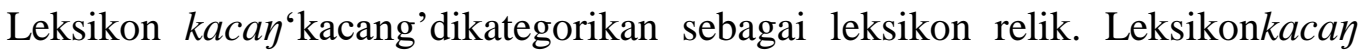
'kacang'dalam proses alur pewarisannya tidak mengalami perubahan sedikit pun dari bahasa Jawa kuna: kacay 'kacang', baik pada bentuk maupun arti. Leksikon Jawa kuna

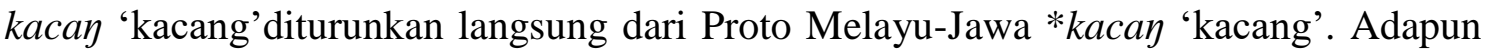
proses alur pergerakan pewarisannya, sebagai berikut. 


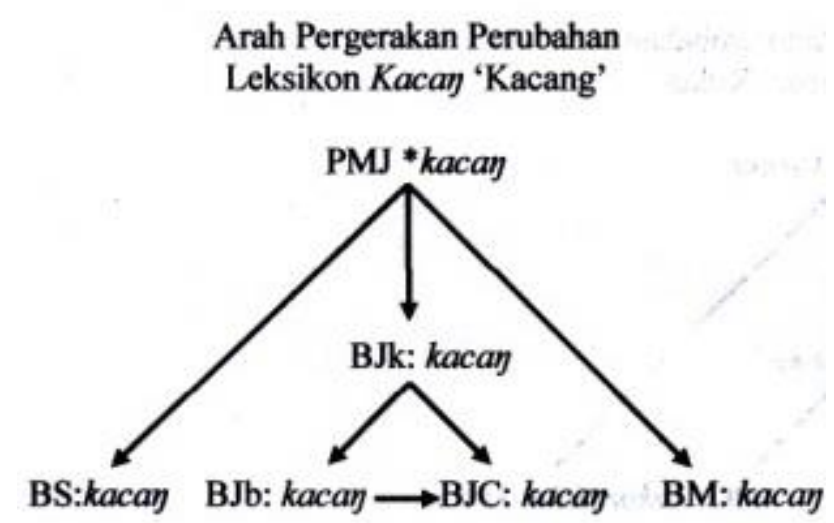

Leksikon kacay 'kacang' yang terdapat dalam BJC adalah leksikon asli dan relik, yakni sebagai warisan langsung dari BJk dan BJb.

\section{Leksikon Relik: Kitaq 'Kita'}

Leksikon kitaq 'kita'dikategorikan sebagai leksikon relik. Leksikon kitaq 'kita'dalam proses alur pewarisannya tidak mengalami perubahan sedikit pun dari bidang bentuk maupun arti. Langsung diwariskan dari bahasa Jawa kuna: kitaq 'kita'. Leksikon Jawa kuna kitaq 'kita'diturunkan langsung dari Proto Melayu-Jawa *kitaq 'kita'.

Leksikon *kitaq 'kita'diturunkan langsung dari bahasa Jawa kuna. Pada pewarisan ini ditandai dengan ciri dialektal bahasa Jawa dialek Carita, yakni semua fonem /a/ pada akhir kata mengalami pelemahan menjadi /2/.Adapun proses alur pergerakan pewarisannya, sebagai berikut.

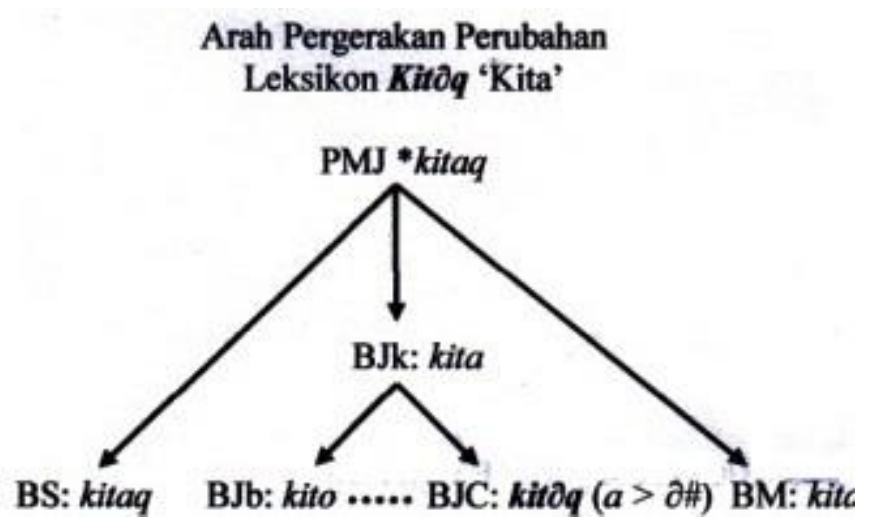

Leksikon Asli: Kain 'Kain' 
Leksikon kain 'kain'adalah leksikon asli yang ditemukan dalam bahasa Jawa dialek Carita. Proses penurunan atau pewarisan leksikon kain 'kain'yang berasal dari bahasa Jawa kuna telah mengalami perubahan internal. Proses perubahan tersebut dapat dijelaskan melalui kaidah linguistic sebagai berikutBJb: kaen $(h>\theta, a-i$ > e) $\rightarrow$ BJC:kaen'kain’

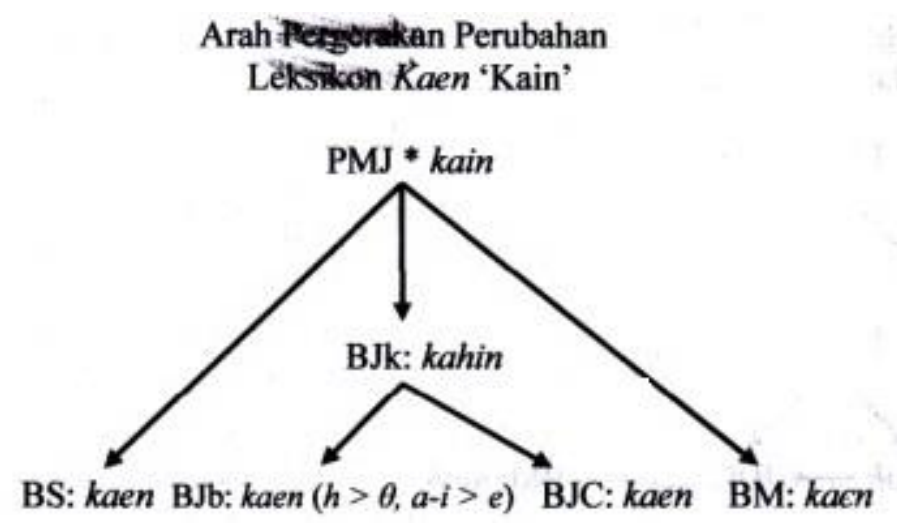

\section{Leksikon Asli: Kurkur 'Kukur'}

Leksikon kurkur 'kukur'adalah leksikon asli yang ditemukan dalam bahasa Jawa dialek Carita. Proses penurunan atau pewarisan leksikon kurkur 'kukur'yang berasal dari bahasa Jawa kuna telah mengalami perubahan internal. Proses perubahan tersebut dapat dijelaskan melalui kaidah linguistic sebagai berikutBJb: $(u-u>u$ - - : disimilasi) $\rightarrow$ BJC:kurkur 'kukur'

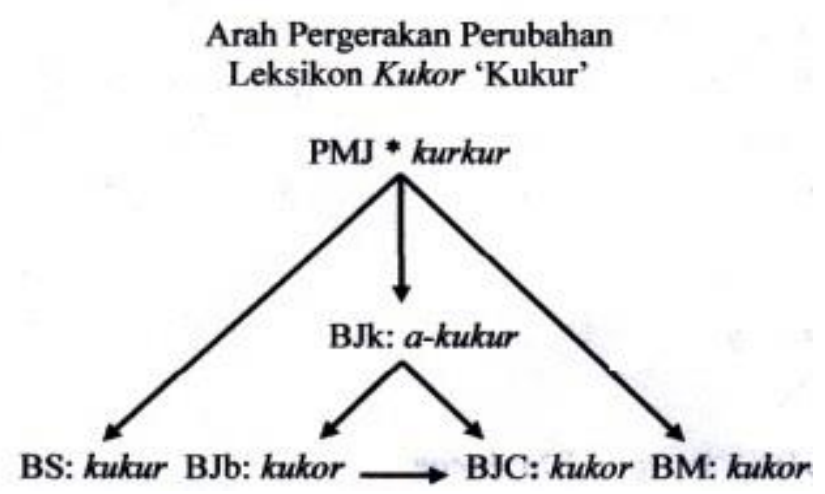

Leksikon kaen 'kain' dalam bahasa Jawa dialek Carita adalah leksikon asli, yang diturunkan dari bahasa Jawa baru dengan perubahan fonemis: $(u-u>u-o$ : disimilasi)

Leksikon Aslidluway 'Kertas'

Leksikon dluway 'kertas'adalah leksikon asli yang ditemukan dalam bahasa Jawa dialek Carita. Proses penurunan atau pewarisan leksikon dluway 'kertas'yang 
berasal dari bahasa Jawa kuna telah mengalami perubahan internal. Proses perubahan tersebut dapat dijelaskan melalui kaidah linguistic: terbentuknya klaster /dl/.

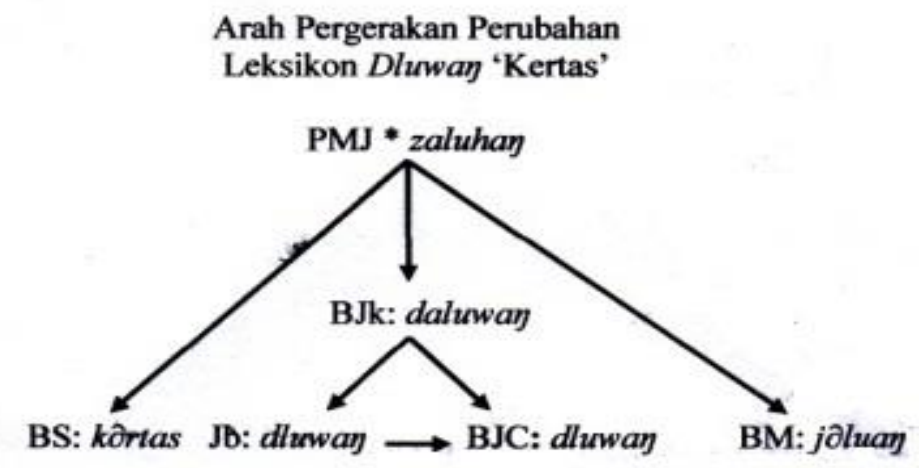

Leksikon dluway 'kertas' dalam bahasa Jawa dialek Carita adalah leksikon asli, yang diturunkan dari bahasa Jawa baru dengan perubahan fonemis, yakni terbentuknya klaster /dll.

\section{Leksikon Inovasi:Tumdq'Kutu'}

Leksikontumdq'kutu'adalah leksikon yang ditemukan dalam bahasa Jawa dialek Carita. Leksikon ini dikategorikan sebagai bentuk inovatif, karena telah mengalami perubahan internal, yakni menyesuaikan harmonisasi bunyi yang berlaku di wilayah pemakaian bahasa Jawa Carita. Adapun alur perubahanya, sebagai berikut.

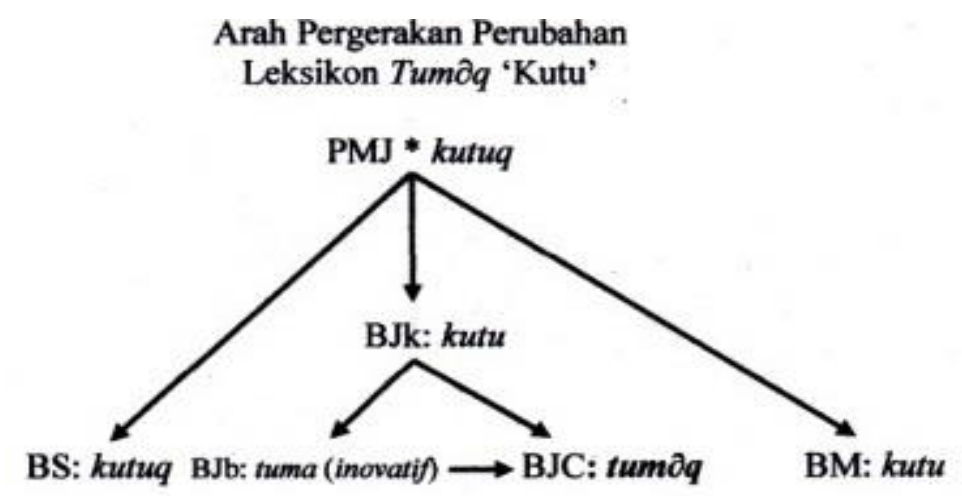

\section{Leksikon Inovasi:Samet 'Sedikit'}

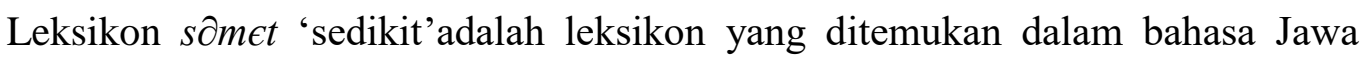
dialek Carita. Leksikon səmet 'sedikit'dikategorikan sebagai bentuk inovatif, karena telah mengalami perubahan eksternal. Perubahan tersebut tidak ada kemiripan fonologis dengan bahasa Jawa kuna, bahasa Jawa baru, bahasa Sunda, dan bahasa Melayu. Proses perubahan bentuk menjadi samet 'sedikit' sukar untuk dijelaskan sesuai kaidah linguistic bahasa Jawa dialek Carita. Adapun alur perubahanya, sebagai berikut. 


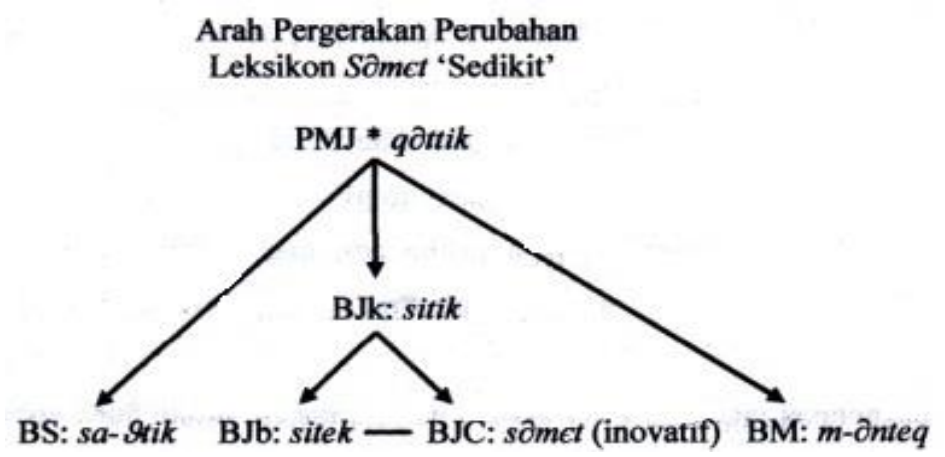

\section{Simpulan}

Hasil penelitian ini memperoleh temuan bahwa wilayah enclave Jawa/kantung Jawa (bahasa Jawa dialekCarita), yang berada di wilayah pemakaian bahasa Sunda, masih menyimpan leksikon-leksikon relik dan asli. Sebagai wilayah kantung, bahasa Jawa dialek Carita tidak dapat dilepaskan terjadinya perubahan dan pergeseran leksikon, baik bentuk maupun arti. Fenomena ini terjadi pada leksikon inovatif.

Bentuk leksikon relik sebagai leksikon yang diturunkan langsung dari bahasa Jawa kuna tanpa perubahan sedikit pun. Bentuk leksikon asli adalah leksikon yang mengalami perubahan pada saat pewarisan, namun perubahan tersebut dapat dijelaskan melalui kaidah linguistic. Leksikon relik dan asli tersimpan pada medan makna perlengkapan tradisional dan emosional hubungan kekerabatan. Faktor eksternal yang mendukung pemertahanan bentuk relik dan asli adalah sikap positif dalam mempertahankan upacara siklus kehidupan.

Arah pergerakam perkembangan bentuk relik dan asli bahasa Jawa dialek Carita cenderung vertical, yakni arah pewarisan yang langsung dari bahasa Jawa kuna. Arah pergerakan perubahan bentuk inivatif cenderung horizontal, yakni arah perubahan yang menyesuaikan kaidah yang dimiliki dalam bahasa Sunda dan Melayu.

\section{Daftar Pustaka}

Hock, Hans Henrich. 1988. Principles of Historical Linguistics. Amsterdam: Mouton de Gruyter.

Iskandarwassid. 1985. Struktur Bahasa Jawa Dialek Banten. Jakarta: Pusat Pembinaan dan Pengembangan Bahasa.

Nothofer, Bernd. 1975. The Reconstruction of Proto Malayo-Javanic. S-Gravenhage: Martinus Nijhoff.

1977. Daialekatlas von West-Java und der Westlichen Gebiete Zentral Javas.Koln: Philosophischen Fakultat.

1987. “Cita-cita Penelitian Dialek”dalam Dewan Bahasa. 31,2. Serawak. 
Patmadiwiria. 1977. Kamus Dialek Jawa Banten-Indonesia. Jakarta: Pusat Pembinaan dan Pengembangan Bahasa.

Pusat Bahasa. n.d. Bahasa Daerah di Indonesia. Jakarta.

Sudaryanto. 1988. Metode Linguistik Bagian Kedua: Metode dan Aneka Teknik Pengumpulan Data. Yogyakarta: Gadjah Mada University Press.

Suryadi, M. 1997. “Carita: Kantung Jawa yang Konservatif”. Makalah dalam Kongres Linguistik Nasional, Surabaya, 7-11 November 1997.

Swadesh, Morris. 1955. "Towards Greater Accuracy in Lexicostatistic Dating." dalam International Journal of American Linguistics 21: 121-137.

Wurm, S.A. dan B. Wilson. 1978. English Finderlist of Reconstructions in Austronesian Languages: Post-Brandstetter. Canberra: The Australian National University 